\title{
Deformation behavior of perfect and imperfect nanomaterials made of intermetallic compounds with $b c c$ lattice
}

\author{
R. I. Babicheva ${ }^{1 \dagger}$, M. D. Starostenkov ${ }^{2}$, K. Zhou ${ }^{1}$ \\ †ri.babicheva@gmail.com \\ ${ }^{1}$ School of Mechanical and Aerospace Engineering, Nanyang Technological University, \\ 50 Nanyang Avenue, 639798, Singapore, Singapore \\ ${ }^{2}$ Altai State Technical University, 46 Lenina St., 656038, Barnaul, Russia
}

\begin{abstract}
The paper reviews the literature devoted to the stress-strain behavior of nanomaterials made of $\mathrm{NiAl}$ and $\mathrm{FeAl}$ intermetallics having B2 superstructure with body-centered cubic $(b c c)$ lattice. Such nanomaterials demonstrate elastic deformation up to the point of their failure. In a concave region of a strain dependence of the potential energies $P(\varepsilon)$, the materials demonstrate thermodynamic instability and the non-homogeneous elastic deformation which is accompanied by the appearance of domains of two strain levels. Stretching behavior of $\mathrm{NiAl}$ and FeAl nanomaterials depends on lattice defects and sample geometry. An introduction of lattice defects which result in an appearance of residual stresses in structures can lead to the nanomaterial strengthening.
\end{abstract}

Keywords: Molecular dynamics; intermetallic compound; bcc lattice; negative stiffness; dislocation.

\section{Introduction}

All nanomaterials can be classified into zero-, one-, twoand three-dimensional. Representatives of these groups are, for example, nanoparticles, nanowires, nanofilms and so-called bulk nanomaterials, respectively. The zero-, oneor two-dimensional nanomaterials which are also called as disperse nanomaterials, having at least one dimension in the nanoscale level, very often demonstrate strength approaching the theoretical strength limit $[1-4]$. The threedimensional nanomaterials are polycrystalline metals and alloys having nanocrystalline or ultrafine grain structures for which three arbitrarily dimensions above $100 \mathrm{~nm}$. According to the Hall-Petch relation $[5,6]$ the yield stress of polycrystalline materials increases with decrease in their average grain size. This principle underlies the grain size strengthening of the material. That is why the bulk nanomaterials produced by severe plastic deformation methods demonstrate extraordinary high strength [7-16]. Usually such grain refinement is reached via severe plastic deformation methods, such as HPT and ECAP, though for some metallic materials, a reduction of grain size down to the nanoscale level or even structure amorphization can be obtained by using conventional multipass cold rolling $[17,18]$.

The rapidly developing elastic strain engineering deals with the ability of some nanomaterials to demonstrate extremely high strength during their elastic deformation up to unusually large strain [19]. Especially it is common for brittle nanomaterials, such as intermetallic compounds and silicon [20]. Li et al. [21] have observed that body-centered cubic $(b c c)$ nanowires under tension can show unusually large reversible strain by a reversible twinning mechanism. It has been found that there exists a critical size of three-layer $\mathrm{Cu}-\mathrm{Ni}-\mathrm{Cu}$ nanowires to exhibit pseudoelastic behavior [22] In addition, $\mathrm{Ni}$ et al. [23] concluded that the pseudoelasticity in Co nanowires is relevant to their length and cross-section size.

The mechanism of non-homogeneous elastic deformation or "two-phase stretching" has been described as exemplified by DNA molecular chains by Savin et al. [24]. If the monomer stretching energy as a function of extension has a non-convex (concave up) region (see Fig.1), the stretching of the polymer chain separates into two phases: weakly and strongly stretched monomers. Within the two-phase stretching regime, strain increases at constant stress. This is because the two-phase stretching does not follow the non-convex $P(\varepsilon)$ curve but develops along the lower energy path shown in Fig.1 by the dashed line, which is the tangent to the $P(\varepsilon)$ curve. Linear of $P(\varepsilon)$ dependence implies that $\sigma \sim d P / d \varepsilon$ is constant. For $\varepsilon<\varepsilon_{1}$ the chain undergoes single-phase stretching. In the region where $\varepsilon_{1}<\varepsilon<\varepsilon_{2}$, the domains with strain $\varepsilon_{1}$ and $\varepsilon_{2}$ coexist and elongation occurs due to the growth of the domains with

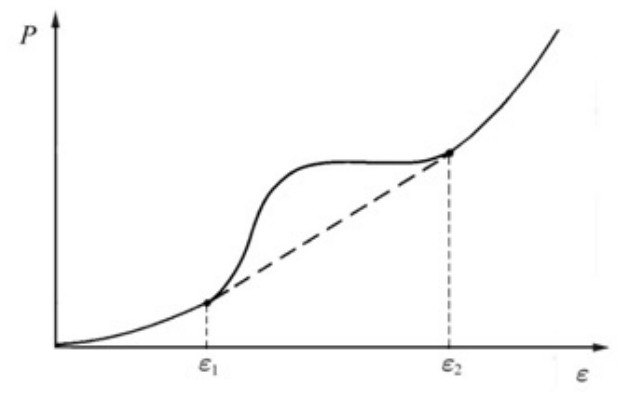

Fig. 1. Schematic representation for the non-convex shape of $P(\varepsilon)$. 
larger strain in expense of the domains with smaller strain. When $\varepsilon$ reaches the value of $\varepsilon_{2}$, the domains with smaller strain disappear and further elongation develops homogeneously. Note that the use of the term "phase" in the work [24] is not actually justified because the chain has only one phase at two different strain levels.

Due to limitations caused by size effect and difficulty of sample preparations, sometimes an investigation of nanomaterial deformation mechanisms through experimental is challenging. Moreover, nanomaterials having the non-convex region in $P(\varepsilon)$ curves and thus demonstrating the thermodynamic instability and negative rigidity during deformation can be affected by many factors, such as temperature [25,26], structure defects [27], etc. The possibility of the creation of thermodynamically stable composite materials with the use of inclusions with a negative stiffness has been demonstrated in $[28,29]$.

In the works [30-47] the new concepts were developed to describe the conditions of formation of transient-stability condensed systems and their structure. The materials under study are generally the alloys and compounds that undergo second-order structural phase transitions. In the vicinity of structural phase transformations the anomalies of structure and properties are observed. An attempt has been made to develop the new concept of phase transition instead of the traditional one by considering not a single point of the transition but a range of values of the parameter that controls the transition. The structural state of a material in this interval is weakly stable with respect to the influence of slight variations of the controlling parameter. It is evident that in this thermodynamically and structurally weakly defined state the effect of the structure defects on the structural phase transformations of the system is significant.

It is believed that metallic materials having fewer number of slip systems than pure metals, such as intermetallic nanomaterials can demonstrate larger elastic strain to failure. Thus, it has been shown recently in a number of works that the similar with DNA deformation behavior can be observed in $\mathrm{NiAl}$ and FeAl intermetallic nanomaterials $[25,27,48-50]$. The current paper reviews the works devoted to molecular dynamics (MD) study of elastic deformation behavior of $\mathrm{NiAl}$ and $\mathrm{FeAl}$ nanofilms and nanowires using the atomic/molecular massively parallel simulator (LAMMPS) program package [51].

\section{Non-homogeneous elastic deformation of $\mathrm{NiAl}$ and $\mathrm{FeAl}$}

In Fig.2a, the $b c c$-lattice of $\mathrm{NiAl}$ and FeAl intermetallic compounds having an ordered B2 type superstructure with a lattice parameter a (2.8712 and $2.852 \AA$, respectively) is shown. The non-homogeneous deformation of $\mathrm{NiAl}$ and FeAl nanomaterials, in particularly, their nanofilms and nanowires, can be explained by the peculiarity of potential energy curves for these systems similar to that for the DNA chain $[24,48,50]$. If the potential energy $E$ as a function of strain $\varepsilon$ under uniform tension of a nanowire has a convex segment (Fig.2), the non-uniform deformation at which the

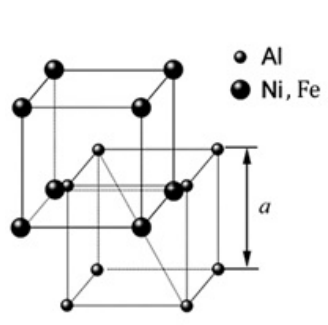

a

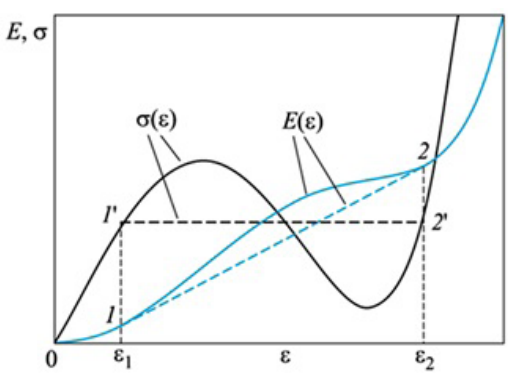

$\mathrm{b}$
Fig. 2. (a) B2 superstructure based on the bcc lattice with the lattice parameter a $\mathrm{Al}(\mathrm{Ni}, \mathrm{Fe})$ atoms are shown by small (large) spheres. (b) Schematic strain dependences of the potential energy density $\mathrm{E}$ and stress $\sigma=d E / d \varepsilon$ for a nanofilm in the case of uniform (solid lines) and non-uniform (dashed lines) deformation. Line 1-2 is the tangent of the $E(\varepsilon)$ curve at points $\varepsilon_{1}$ and $\varepsilon_{2}$. The $\sigma(\varepsilon)$ curve has an unstable segment with a negative elastic constant $d \sigma / d \varepsilon$. The image is represented from [49].

system follows tangent $1-2$ with the lower energy $E(\varepsilon)$ than in the convex segment is more favorable. The linear dependence of $E(\varepsilon)$ implies that the stress $\sigma(\varepsilon)=d E / d \varepsilon$ is constant in the interval $\varepsilon_{1}<\varepsilon<\varepsilon_{2}$ (shown by the dashed straight line 1'-2'). In this interval, the elongation of the nanowire occurs through absorption of less deformed domains $\left(\varepsilon_{1}\right)$ by more deformed domains $\left(\varepsilon_{2}\right)$. At $\varepsilon=\varepsilon_{2}$, domains with the strain $\varepsilon_{1}$ disappear completely. A further tension is uniform. The presence of a region with a negative slope in the $\sigma(\varepsilon)$ curve means the negativity of elastic constant $d \sigma / d \varepsilon$, i.e., the thermodynamic instability of deformation.

Note that the stress-strain relation for small and large computational cells of the intermetallic compounds differs within the unstable region and in the region close to the strength limit. It can be clearly seen from Fig.3, where stressstrain curves are shown for NiAl nanofilms having small ( $L_{\mathrm{x}}=3 a$, dashed line) and large sizes $\left(L_{\mathrm{x}}=200 a\right.$, solid line) in the direction of tensile loading $\left(L_{\mathrm{x}}\right)$. The difference is associated with different deformation mechanisms in small and large computational cells. In the small computational cell, the deformation is uniform (homogeneous) and domains of different strain are not formed, while in the large cell, there is a coexistence of domains with lower and higher degree of elastic strain in the region of thermodynamic instability (see Fig.4a and b). In this region, nanofilms are elongated due to the absorption of the domains with a lower strain degree by those with a higher strain.

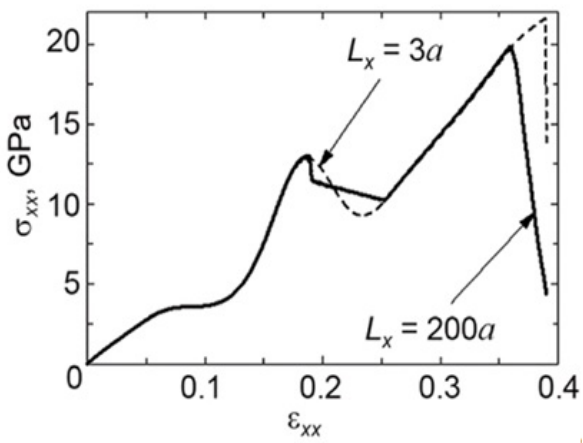

Fig. 3. Tensile stress-strain curves for NiAl nanofilms [50]. Results for large (small) computational cell are shown by solid (dashed) curve. 


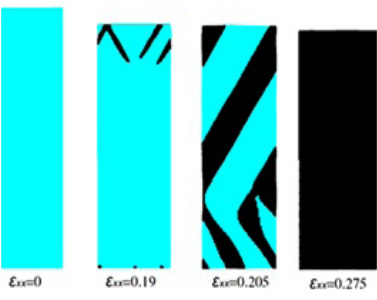

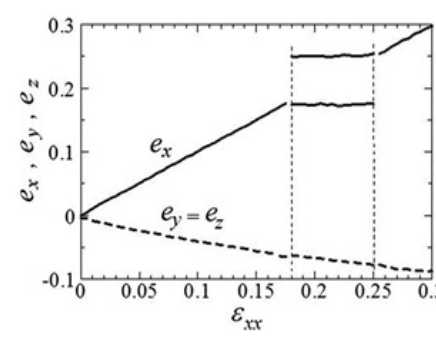

$\mathrm{b}$
Fig. 4. Results for large computational cell. (a) Regions with lattice strain $e_{x}>0.2(<0.2)$ are shown in black (blue). An average tensile strain $\varepsilon_{x x}$ is indicated for each panel. (b) Local lattice strains $e_{x}$ and $e_{y}$ $=e_{z}$ as the functions of $\varepsilon_{x x}$. In the thermodynamically stable regions, $e_{x}=\varepsilon_{x}$. In the unstable region, there exist two types of domains where $e_{x}=0.18$ and 0.25 , and these values do not change with increase in $e_{x}$. The deformation here occurs by growth of the domains with larger $e_{x}$ in expense of the domains with smaller $e_{x}$.

Figure 5 shows the stress-strain curves of NiAl nanofilm loading and unloading for the case of the large computational cell. The curves coincide, except for the regions of domain nucleation, indicating complete reversibility of deformation during forward and backward transition of the nonhomogeneous deformation interval. In this region, both the loading and unloading processes follow a single straight line with a negative slope implying the negative rigidity of a system.

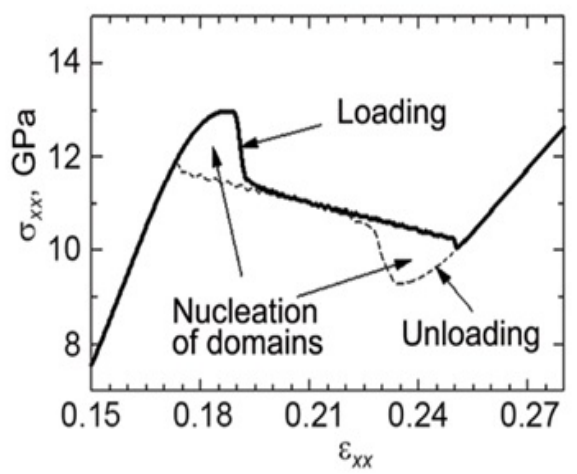

Fig. 5. Stress-strain curves of NiAl nanofilm loading and unloading for large computational cell [50].

\section{Effect of dislocation and notch presence on deformation behavior}

The influence of defects on the non-homogeneous elastic deformation behavior has been studied via introducing $\mathrm{N}$ prismatic dislocations and a notch to $\mathrm{NiAl}$ computational cells (Fig.6).

In Fig.7, the tensile deformation stress-strain curves for the computational cell with one dislocation and for that having $\mathrm{N}=11$ dislocations and the notch are shown. In the former case, the curve can be divided into four regions labeled as I-IV (Fig. 7a). It is seen that, unlike this case, the curve for the cell with 11 dislocations and the notch has five such regions (labeled as I-V in Fig.7b) with two the regions of non-homogeneous deformation (Regions II and IV)
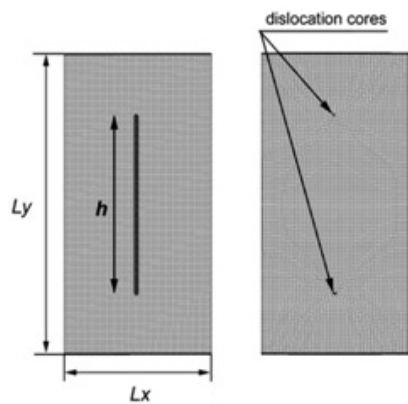

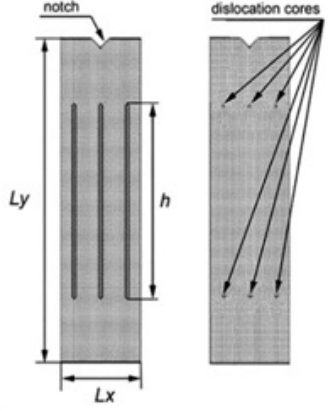

$\mathrm{b}$
Fig. 6. NiAl computational cells with (a) one prismatic dislocation before (on the left) and after relaxation (on the right) and those with $\mathrm{N}$ prismatic dislocations (here $\mathrm{N}=3$ ) and the notch before (on the left) and after relaxation (on the right).

when strongly and weakly deformed domains coexist in the nanofilm. In Region I, inner and the outer parts of the notched nanofilm (see Fig.8a) deform almost homogeneously even though the former is strained stronger due to the presence of dislocation loops in this part of the cell. In Region II, the deformation of the outer parts of the nanofilm remains nearly homogeneous but the inner part deforms strongly nonhomogeneously. Here strongly and weakly strained domains with sharp boundaries appear. In Region III, the inner and outer parts of the nanofilm are again deformed almost homogeneously, while the further deformation leads to the second non-homogeneous stretching region (Region IV). Region $\mathrm{V}$ is associated with cracking at the notch. For both the computational cells, the nanofilms deform elastically up to the point of maximal tensile stress $\sigma_{x x}^{*}$ and strain $\varepsilon_{x x}^{*}$.

The deformation of the nanofilms in Regions II and IV (for the notched nanofilm) occurs due to the growth of the domains with larger elastic strain in expense of the domains with smaller elastic strain. For both the domain types, a primitive cell of the strained B2 superstructure has the shape of parallelepiped, i.e., it has the same symmetry of bodycentered tetragonal lattice.

It has been demonstrated recently that residual stresses created by lattice defects in nanofilms can lead to their additional strengthening $[27,52]$. For example, it has been found that the notched $\mathrm{NiAl}$ nanofilm can be strengthened by introducing residual compressive stresses in the outer parts of the nanofilm [27]. This is achieved by introducing an array of

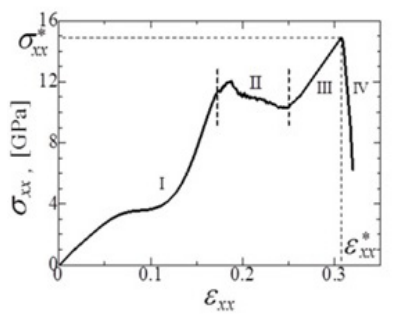

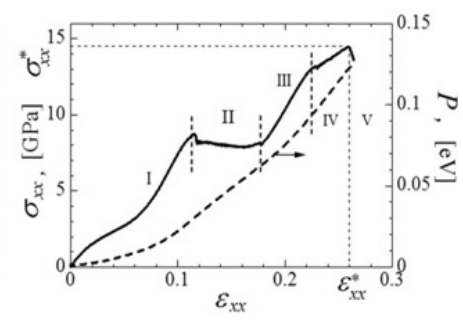

b
Fig. 7. Stress-strain curve for the NiAl computational cell with one dislocation (a) and for that with 11 dislocation loops and notch at surface (b). Potential energy per atom $\mathrm{P}$ as a function of tensile strain is plotted by dashed line. At the point of maximal tensile stress $\sigma_{x x}^{*}$ and strain $\varepsilon_{x x}^{*}$, brittle fracture of the nanofilms occurs. 


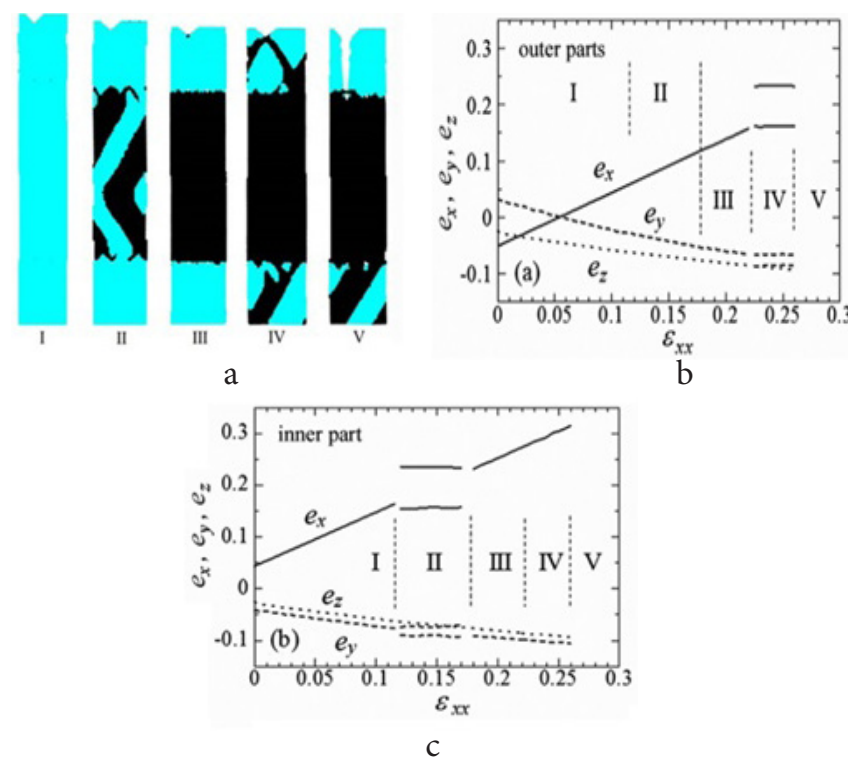

Fig. 8. (a) Regions with dislocations $(N=11)$ and notch, regions with local lattice strain $e_{x}<0.2\left(e_{x}>0.2\right)$ are shown in blue (black). In (b) and (c), local lattice strains $e_{x}, e_{y}$ and $\varepsilon_{x x}$ as a function of uniaxial tensile strain $\varepsilon_{x x}$ are plotted for the outer and inner parts of the nanofilm, respectively.

prismatic dislocation loops in the inner part of the nanofilm. Such nanofilms demonstrate not only higher strength but also higher strain and energy to failure compared to those without prismatic dislocations (Fig.9). These results open a new way (the introduction of residual stresses) of disperse nanomaterial strengthening.

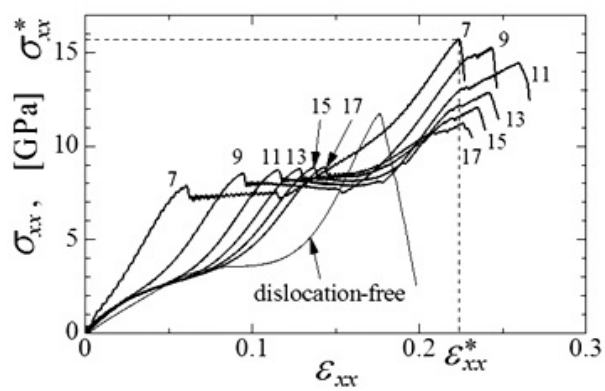

Fig. 9. Stress-strain curves for the notched $\mathrm{NiAl}$ nanofilms with the dislocation loops introduced with the period of $\mathrm{Na}$ ( $\mathrm{N}$ indicated for each curve). For comparison, the stress-strain curve of the notched dislocation-free nanofilm is shown by the thin line. Maximal tensile stress and strain to failure are denoted as $\sigma_{x x}^{*}$ and $\varepsilon_{x x}^{*}$, respectively [27].

\section{Effect of computation cell geometry}

Another factor which influences the stress-strain behavior of $\mathrm{NiAl}$ and $\mathrm{FeAl}$ intermetallic nanomaterials is their geometry or shape [49]. In Fig.10, the stress-strain curves for $\mathrm{NiAl}$ and $\mathrm{FeAl}$ nanofilm and nanowire free of defects are shown. For both the intermetallic compounds, a slope of the curves in the thermodynamically unstable non-homogeneous deformation region is negative and positive for the nanofilms
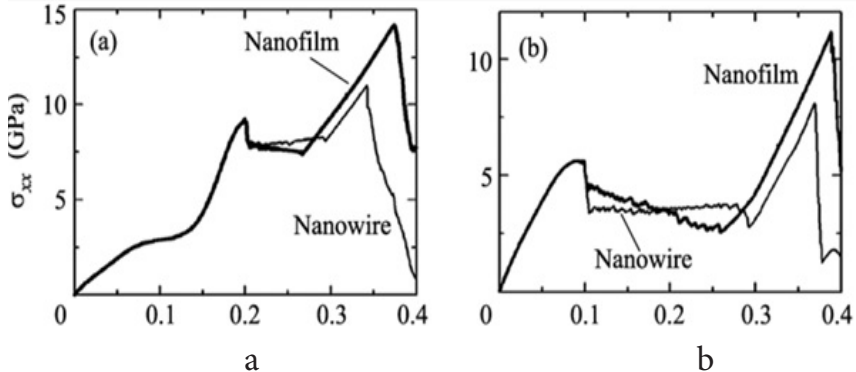

Fig. 10. Stress-strain curves for nanofilm (thin line) and nanowire (thick line): (a) NiAl and (b) FeAl [49].

and nanowires, respectively. Such difference in the slopes can be explained by the particularity of a nucleation and motion of domain walls in the nanomaterials.

In the nanofilms and nanowires, domains nucleate on a flat surface and at an edge, respectively. In three mutually perpendicular cross sections of the computational cells (Fig.11), it can be clearly seen that the domains in the nanowire nucleate at one of the edges, whereas the domains in the nanofilm nucleate on the free surface. Migration of domain walls in the nanowire occurs from one corner of the square cross section to the opposite one, whereas in the nanofilms, their migration occurs from one free surface to the opposite one. Features in the motion of the domain walls likely explain the difference between the slopes of the stressstrain curves in the non-homogeneous deformation region.

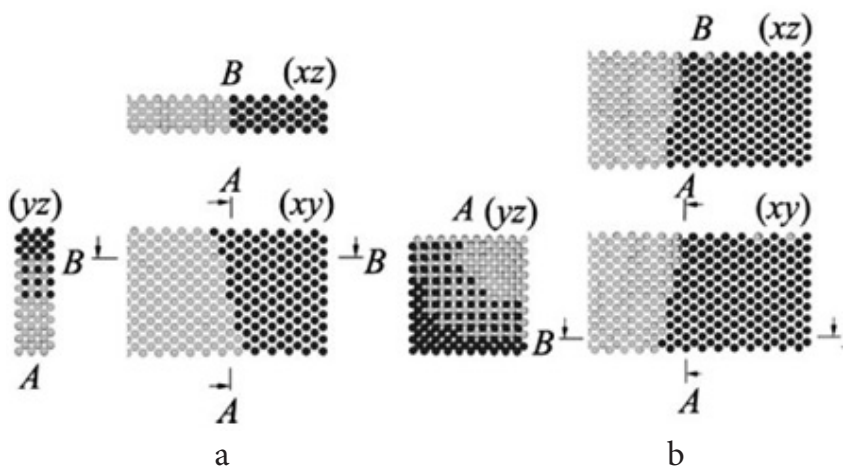

Fig. 11. Scheme of the stepwise migration of domain walls: (a) nanofilm and (b) nanowire [49]. Dark and light points indicate bcc unit cells with larger and smaller elastic deformation, respectively

\section{Summary}

The work considers the deformation behavior of perfect and imperfect nanomaterials made of $\mathrm{NiAl}$ and FeAl intermetallic compounds having $b c c$ lattice.

The nanomaterials deform elastically up to their failure. During the manifestation of thermodynamic instability, the elastic deformation of nanofilms and nanowires occurs nonhomogeneously and is accompanied by structure splitting into domains with higher and lower degree of elastic deformation.

Stretching behavior of the NiAl and FeAl nanomaterials is dependent on sample geometry due to difference in the domain migration. The other important factors are defects and residual stress distributions. For instance, due to 
formation of compressive residual stresses near surfaces of nanofilms, series of prismatic dislocations located at a certain distance from each other inside these nanofilms leads to an appearance of second non-homogeneous elastic deformation region at a higher strain level.

The results demonstrate that the strengthening by introducing internal stresses which are widely used for bulk structures can also be applied for intermetallic nanomaterials having B2 superstructure.

Rita I. Babicheva acknowledges the Singapore International Graduate Award (SINGA) for providing her PhD scholarship.

This study was financially supported by the Russian Foundation for Basic Research, grant No 14-08-90416-Ukr_a.

\section{References}

1. C. Bai, M.Liu. Nano Today. 7, 258 (2012).

2. J.R. Greer, D. Jang, X. W. Gu. JOM. 64, 1241 (2012).

3. T. Zhu, J.Li. Prog Mater Sci. 55, 710 (2010).

4. J.R. Greer, J.T. M. De Hosson. Prog. Mater. Sci. 56, 654 (2011).

5. E. O. Hall. Physical Society - Proceedings. 64(381B), 747 (1951).

6. N. J. Petch. Iron and Steel Institute - Journal. 174,25 (1953).

7. Y. Estrin, A. Vinogradov. Acta Mater. 61, 782 (2013).

8. A.P.Zhilyaev, T. G. Langdon. Prog. Mater. Sci. 53, 893 (2008).

9. O. Sitdikov, E. Avtokratova, R. Babicheva, T. Sakai, K. Tsuzaki, Y. Watanabe. Mater. Trans. 53(1), 56 (2012).

10. M. Zehetbauer, R. Grössinger, H. Krenn, M. Krystian, R. Pippan, P. Rogl, T. Waitz, R. Würschum. Adv.Eng. Mater. 12(8), 692 (2010).

11. R.Z. Valiev, I. Sabirov, A.P. Zhilyaev, T.G. Langdon. JOM. 64(10), 1134 (2012).

12. R.I. Babicheva, S.V. Dmitriev, Y. Zhang, S.W. Kok, K. Zhou. J. Nanomater. 231848, (2015).

13. Z.X. Wu, Y.W. Zhang, M.H. Jhon, J. R. Greer, D. J. Srolovitz. Acta Mater. 61, 1831 (2013).

14. R.Z. Valiev, M.J. Zehetbauer, Y. Estrin, H.W. Höppel, Y. Ivanisenko, H. Hahn, G. Wilde, H.J. Roven, X. Sauvage, T. G. Langdon. Adv. Eng. Mater. 9, 527 (2007).

15. O.Sh. Sitdikov, E.V. Avtokratova, R.I. Babicheva. Phys. Met. Metallogr. 110(2), 153 (2010).

16. R.I. Babicheva, S.V. Dmitriev, Y. Zhang, S.W. Kok, N. Srikanth, B. Liu, K. Zhou. Comput. Mater. Sci. 98, 410 (2015).

17. R.I. Babicheva, Kh.Ya. Mulyukov, Appl. Phys. A-Mater. 116(4), 1857 (2014).

18. R. I. Babicheva, Kh. Ya. Mulyukov, I.Z. Sharipov, I. M. Safarov. Phys. Solid State. 54(7), 1480 (2012).

19. H Pan, YW Zhang. J. Phys. Chem. C. 116(21), 11752 (2012).

20. P. Lin, R.I. Babicheva, M. Xue, H.S. Zhang, H. Xu, B. Liu, K. Zhou. Comput. Mater. Sci. 96, 295 (2015).

21. S. Li, X. Ding, J. Deng, T. Lookman, J. Li, X. Ren, J. Sun, A. Saxena. Phys. Rev. B82, 205435 (2010).

22. N. Abdolrahim, I. N. Mastorakos, H. M. Zbib. Phys. Rev. B81, 054117 (2010).
23. C. Ni, H. Ding, C. Li, L.T. Kong, X. Jin. J. Scripta Mater. 68(3-4), 191 (2013).

24. A.V. Savin, I.P. Kikot, M.A. Mazo, A.V. Onufriev, P. Natl. Acad. Sci. USA. 110, 2816 (2013).

25. K.A. Bukreeva, R.I. Babicheva, S.V. Dmitriev, K. Zhou, R. R. Mulyukov, A. I. Potekaev. Russ. Phys. J. 57(1), 69 (2014).

26. K.A. Bukreeva, R.I. Babicheva, A.B. Sultanguzhina, S. V. Dmitrieva, K. Zhou, R. R. Mulyukov. Phys. Solid State. 56(6), 1157 (2014).

27. R.I. Babicheva, K.A. Bukreeva, S.V. Dmitriev, R. R. Mulyukov, K. Zhou. Intermetallics 43, 171 (2013).

28. W.J. Drugan. Phys. Rev. Lett. 98, 055502 (2007).

29. D. M. Kochmann, W.J. Drugan. Proc. R. Soc. A468, 2230 (2012).

30. A. I. Potekaev, V. V. Kulagina. Izv. Vyssh. Uchebn. Zaved. Fiz. 56(1/2), 202 (2013).

31. A. I. Potekaev, V. V. Kulagina. Russ. Phys. J. 54(8), 839 (2011).

32. M.D. Starostenkov, A.I. Potekaev, N.V. Sinitsa, et al. Russ. Phys. J. 53(8), 809 (2010).

33. V.D. Klopotov, A.A. Klopotov, A.I. Potekaev, et al. Izv. Vyssh. Uchebn. Zaved. Fiz. 56(1/2), 224 (2013).

34. M.D. Starostenkov, A.I. Potekaev, N.V. Sinitsa, et al. Russ. Phys. J. 54(2), 172 (2011).

35. M.D. Starostenkov, A.I. Potekaev, N.V. Sinitsa, et al. Russ. Phys. J. 54(3), 308 (2011).

36. M.D. Starostenkov, V.V. Kulagina, A.I. Potekaev. Fund. Probl. Sovr. Materialoved. 8(3), 367 (2012).

37. A.I. Potekaev, S. V. Makarov, V.A. Plotnikov. Russ. Phys. J. 54(3), 314 (2011).

38. V.M. Savostikov, A.I. Potekaev, A.N. Tabachenko. Russ. Phys. J. 54(7), 756 (2012).

39. A.I. Potekaev, A.A. Klopotov, E. V. Kozlov, V.V. Kulagina. Izv. Vyssh. Uchebn. Zaved. Fiz. 56(1/2), 213 (2013).

40. A.I. Potekaev, A.A. Chaplygina, V.V. Kulagina, et al. Russ. Phys. J. 56(6), 620 (2013).

41. A.I. Potekaev, A.A. Chaplygina, V.V. Kulagina, et al. Russ. Phys. J. 55(7), 814 (2012).

42. A.I. Potekaev, A.A. Chaplygina, V.V. Kulagina, et al. Russ. Phys. J. 55(11), 1248 (2013).

43. A.I. Potekaev, S. V. Makarov, V.A. Plotnikov. Russ. Phys. J. 56(6), 630 (2013).

44. A.I. Potekaev, A.A. Klopotov, Yu. V. Ivanov, V.V. Kulagina. Russ. Phys. J. 54(9), 1012 (2012).

45. A. I. Potekaev, A. A. Klopotov, Yu. V. Ivanov, Sch. G. Volokitin. Russ. Phys. J. 56(8), 914 (2013).

46. M.D. Starostenkov, A.I. Potekaev, A.V. Markidonov, et al. Russ. Phys. J. 54(11), 1241 (2012).

47. A.I. Potekaev, V.V. Kulagina, A.A. Klopotov, M.D. Starostenkov. Russ. Phys. J. 55(4), 353 (2012).

48. K.A. Bukreeva, R.I. Babicheva, S.V. Dmitriev, K. Zhou, R. R. Mulyukov. Phys. Solid State. 55(9), 1963 (2013).

49. K.A. Bukreeva, R.I. Babicheva, S. V. Dmitriev, K. Zhou, R. R. Mulyukov. JETP Letters. 98(2), 91 (2013).

50. R.I. Babicheva, K.A. Bukreeva, S.V. Dmitriev, R. R. Mulyukov, K. Zhou. CMST. 19(3), 127 (2013).

51. S. Plimpton. J. Comput. Phys. 117, 1 (1995).

52. K Zhou, A.A. Nazarov, M.S. Wu. Philos. Mag. 88, 3181 (2008). 